\title{
Changing Rural Graphics and Feminist Readings in a Third World Locale: The Case of "Aathi"
}

\author{
Rajeev Kumaramkandath ${ }^{1}$ and Sindu Antherjanam ${ }^{2}$ \\ ${ }^{1}$ Assistant Professor, Christ University, Bengaluru, Karnataka, India \\ ${ }^{2}$ Assistant Professor, Sanathana Dhama College, Alappuzha, Kerala, India \\ E-Mail: rkkandath@gmail.com,dr.sindhuantherjanam@gmail.com
}

\begin{abstract}
Development and environmental discourses are two sites that determine the Third world experience today. The paper maps the nuances associated with the emerging feminist narratives that are concerned with the degenerating ecologies and the feminine side of the same. While development feeds on the memories of underdevelopment it also creates nostalgias, protests, marginalizes subjectivities and a new time of degeneracy where environment is all over the discussions. The well-known Malayalam writer Sara Joseph's novel “Aathi” is discussed here in order to understand how the feminist articulation of concerns around environmental degradation leads to new geographies to resistance.

Keywords: Underdevelopment, environmentalism, feminist narrative, Third World, Aathi, Sara Joseph
\end{abstract}

\section{INTRODUCTION}

The drastic transitions in the ecological balance, the burgeoning corporate sector and the reclusive state are three signifiers that perhaps powerfully communicate the contemporary Third world political spheres. These signifiers, each of them, have a peculiar but different relationship with the zodiac that encapsulates them, that is the development discourse. In other words they, each of them, invoke different, and sometimes mutually exclusive but still interrelated, discussions about the overarching themes of state and development. In the mainstream discourses of development these issues, however, are still side lined. While ecology has managed to gain much visibility in the public sphere the remaining two, that is the states' withdrawal and corporatization, still remain implicit and more or less invisible or not discussed much. Nevertheless within the emerging frames of resistance these three have an intertwined existence where one (the environmental discourse) cannot be fully understood without understanding the other two. In a changed world development discourses also do not have an easy life. They are very often criticized for the heavy involvement of corporate houses as well as international funding agencies that has produced new circuits of global dependence. This is apart from the environmental_criticism. Nevertheless the imagination of development has always flourished, and they still do, by feeding on the memories and fears of underdevelopment.

In a way shielding of development as a necessary process to overcome the evils of underdevelopment makes sense as, as
Denis Goulet once remarked, it "invokes shock, manifests squalor, disease, unnecessary deaths and hopelessness" (Goulet 1971, 20). Developmentalism, rephrased in the $21^{\text {st }}$ century as globalism, then draws perennially from the conditions and memories of underdevelopment in a Third world location. The socio-economic language of under/development is an eternal haunting for the Third world subjectivity that then engages in the spree for a materially affluent, welfarist and secured state of life. The feeling of underdeveloped then is the most significant boon for a corporate led developmentalism. Lack of infrastructure, weak health systems, fewer employment opportunities - these and more such 'lacks' - are the everyday frames for regenerating this feeling. They offer lucrative opportunities for the apostles of development to make 'proper' and rational interventions to rectify the state of remaining poor.

This paper examines how this spree for development is contested in the feminist narrative articulated in the Malayalam novel Aathi. Written by Sara Joseph, a wellknown author known for her active membership in the regional feminist movements and for her leftist leanings (James 1995, 109), the novel dwells inside the domains of underdevelopment, pollution, urbanization and so on and so forth. In a way, the novel belongs to the genre of the standard feminist-ecological narratives. Such narratives form an important part of the contemporary environmental discourses that Muhlhausler and Peace (2006) observes as "vastly increased in recent decades in response to the worldwide awareness of the global environmental crisis, and which is produced from numerous .... linguistic backgrounds" (2006, 458). From its early phases, feminism and feminists have remained very articulate about changing ecologies and its impact on women's lives. Whether termed as eco feminism or not, feminism, in general, has always remained in agreement that the environmental hazards of development have a specific impact on women. In fact, an anthology published in 2012 that contains readings of a variety of texts, announced as its aim "to examine ...that there is a connection between environmental degradation and the subordination of women” (Vakoch 2012, 12).

It depicts the contrast between the human's desire for material progress and the picturesque background of a village in the south Indian state Keralam. The novel 
deliberately avoids the overtones of nostalgia and even that of despair to considerable extent which are, to a larger degree, hallmark features of narratives of this genre. It instead portrays energies of resistance, rather than overcrowding the reader with jargons of resistance, as built into the flesh and blood existence of the local which gets reflected through the forty-six stories that the story writers inside the novel narrate. Narrated by a feminist author the novel simultaneously attempts to rearticulate the feminine side of this oppression-resistance model without explicitly invoking female bodies or subjectivities per se. The novel falls in the domain of women's writings and feminist articulations that have overwhelmingly been spreading to wider areas, especially including the environmental concerns, over the past several decades.

\section{II.WOMEN'S WRITING TO THE ARGUMENTATIVE FEMINIST}

The dynamic links that exist between text and context have always been at the centre of studies in literature. Whereas a text may or may not be an unproblematic representation of a context it is almost beyond any challenge that the context always has a critical role in the production of a text. Literature is also part of an evolutionary process entangled within the time and space. The passages of thoughts and their creative manifestations should be viewed against the changing configurations of a culture, embedded within specific histories. Then we experience the dynamic presence of authors who illuminate their surroundings through insightful interventions. Here, the individual subjectivity becomes an explicit construction of the social surroundings inviting the reading critique to engage with this relationship in its depths. It is not merely in the deployment of the syntax of the language but rather in an articulation of the creative energy that the existential issues, confronting a social-cultural-economic-political context, are depicted efficiently.

Coming back to the point here, with the dawn of 20th century women's writing has started assuming the role of being the creative manifestation of women's liberation movements. This was a time when the need for a subjective language, than an objective one, that would address the oppressive structures was felt widely. The distance from the individual experiences to the social structures that, until then, had an objective existence, was contested and mitigated, if not totally problematized, by women writers whose writings primarily attempted to work as revelations or reflections of the subjugated status of women in the society. This trend was extremely relevant and challenging with respect to two contexts: One, that even when women were writing, their writings consciously or unconsciously adopted the parameters of literary articulation that were constructed in a male dominated world. In the absence of a conscious disposition informing creative expressions, it was not uncommon to see that women authors unintentionally fell into the trap of reproducing the patriarchal hegemonies that under lined the production of literature until then. Two, the absence of powerful interventions from the feminine section has invited males to occupy that space. That is to say that this had resulted, this was especially during periods of reformation in both East and West, in men writing for women under pseudonyms of women most often. This was conceived as a major challenge by several women authors during the period as such a situation was literally leading to understandings where the gravity of oppression was caricatured and its brutality utterly compromised.

The male writing about women has commonly been understood as resulting in her representation as a commodity and as an object without any subjective emotions or feelings attached to its bodily existence. Although this has severe exceptions, this has remained a predominant trend in almost all the contexts across the world. This has necessitated, if not triggering, an equally powerful response. The response to the patriarchal depictions of feminine presence in the society in terms of the male sexual extravaganza and/or her needing male protection has taken the form of a radical manifestation of her subjectivity and her subjective/experiential world. Although such responses have been, sometimes, ambivalent they have often assumed different and diverging forms to take on the multi-faceted oppression. Their language also varied considerably from the very beginning. However, as time passed by, it is presumed, the radical spirits are by now normalized and a bit cooled off.

\section{WOMEN'S WRITING IN THE CONTEXT OF KERALAM}

Thus women's writing in the contemporary periods also has to address a larger environment with multiple and complex factors that has a critical role in determining the subjugated role of women in society. Simultaneously this has also resulted in an expansion of the focus of feminist writing to areas that are much beyond the immediate concerns of conventional women's writing. This has also resulted in the creation of a space where feminist authors are no longer considered as merely writing to protect or reflect upon the interests of the women. They are understood as having a major stake in the larger social, cultural and political geographies of the society. One such prominent feature appearing in feminist literature in the last few decades is changing environment as a result of industrialization. This has specially remained the case in the context of India and other Third world locales. By now we all are familiar with the movements related with ecofeminism and its political impact in the larger Indian context. Inspired by this and other similar movements women authors have taken up the cause of environment as not only closely associated with gender concerns but also as a space for them to claim a crucial stake in challenges against the larger patterns of social development.

This has a special significance in the case of Keralam, a small South Indian state that, speaking from cultural, political and historical perspectives have a major presence 
in the larger Indian context. Primarily known for its achievements in social development, for the major presence of leftism in its political sphere, and also for the historical relations that the region had with foreign powers including the Arabs and, later, with the European powers, its region is also well-known for its beautiful landscapes, greenery and long monsoons which sometimes lasts up to 8 months a year. Although much ahead of other Indian states in terms of literacy, healthcare and other social development indices Keralam as a region is backward in terms of industrialization. However, the enormous size of foreign remittance from Malayalis working abroad, mainly in the middle east and other locations including the western Europe and US, have radically altered the-regions social and cultural landscapes. The foreign remittance, primarily deployed to construct buildings, shopping malls, flats and so on has a crucial role in designing the social transformations of the state. This has increased by many times, the employment possibilities of this state inviting migrants, who arrive in huge numbers, from mainly North and north eastern parts of India. However, these trends have also coupled with the demographic pressures that the region as a whole experience with its population density which is one of the highest in the whole country. Thus there is a major conversion of paddy fields and other wet lands, agricultural lands, mountain regions and so on into urban areas used for building apartments, malls, for building roads and for other construction activities. This pattern is perhaps too familiar in a Third world location to discuss specifically; however, in a state that is as tiny as Keralam, the impacts of such transformations are felt with much and much more intensity. In a nutshell, this has remained the larger background against which concerns about the changing environment have been articulated.

The feminist literature has already has a prominent place in the larger literary field of Malayalam. Although Malayalam literature has seen women authors writing poems - as early as in early $19^{\text {th }}$ most of the early writings were confined to expressions of their royal location within the palaces where those authors were located. Women's writing moved beyond the royal confines and mythological boundaries from 1930s onwards with the emergence of such authors as Lalithambika Antharjanam and, later in the 40s, $\mathrm{K}$. Saraswathiyamma. In spite of there being major ups and downs in the historical trajectories of women's writing in Malayalam, it has witnessed the emergence of some very powerful writers including such figures as Madhavikkutty, known as Kamala Das in locations outside Keralam. Sara Joseph, the author of Aadi, is one among the latest in the list of women authors in Malayalam who are known for their ideological dispositions and the brilliant caricaturing of the gender biased structures.

\section{RIDDLES RAISED BY AATHI}

"Aathi" is a highly significant novel in the contemporary milieu; a novel that invites keen attention of the readers on environmental issues. "Aathi" puts forth an ecological perspective of wailing life conditions that are beyond modernist interpretations. The protagonist of the novel is water that carries the secret of life. The introduction deals with the idea of man creating God. The "thampuran" of Aathi land, the "kottil", all throw light on this theme. In "Aathi", there is the sight of the treasure of resources made ready by Nature for all living creatures. But, what does man give in return? This is the question raised by the writer. The novel depicts in a moving fashion how modernism and industrialization pollute natural resources; thereby how man loses his or her very existence. The novel gives the impression of watching a film where Aathi, a small vjllage, becomes the stage of multiple riddles.

Through the story of Hagar in The Bible, the story reveals how the ownership of water is maintained. The mother's intense desire to save her son's life results in the search of water throughout the desert; its solution is given by Nature. The mother wishes to float along with her son in the water which is needed for survival. She immerses in water as a sort of emancipation from all hitherto miseries. Aathi is the abyss to conceal all the impurities of the mind and the body. The author herself views Aathi as armour; a shelter to escape from the disasters; it is also the entity that the modern distressed man lacks.

The characters in Aathi are as holy as Nature depicted in it; especially the woman- characters. They accept change, however, foresee the destruction in future. Shailaja, recognizing the lack of safety in the work at city and in husband's home, takes refuge in Aathi. But, characters including her become stupefied by noticing the toxin that is being prepared by time for Aathi. That detection led them to a return. Kunjimaathu, Dinakaran, Ponmani, Shailaja, all have endeavoured to preserve the sanctity of Aathi.

The land of Aathi waits for nights laden with chronicles, and tells how these chronicles could be altered for the betterment of life. Characters like Noormuhamed arrive to Aathi along with migrating birds. Their evenings, replete with narratives, move Aathi towards a new light. In Aathi, the story takes place in a ritualistic fashion. The narrator wears a traditional skirt of tender coconut leaves and turban; with paintings on the face and juggling a ball in the hands, he stands in the midst of water, and vows in the presence of water. The people who gather around to listen to his words are made to recapitulate his promise. Soon after, the narrative commences. Men who sit on boat and describe the tale are regarded as "Thampuran" by the inhabitants of Aathi. There is specialty in the tales for it takes various shapes and moods in the course of time. The narrators, right from Noormohamed to Gitanjali, pass from the doubt - Can women narrate the story? - to the focus on what is being said by them. Also, they concentrate on how life is benefited by these narrations.

The great temples where people visit for "moksha" are being covered with waste. Fatal diseases emanate from there. This is the result of man's senseless actions. The current status 
of Guruvayoor town is unveiled by the novelist. The condition of the people of Chakramkandatthil is same as that of Kuttanadu, i.e. though surrounded by water, miles have to be passed through to collect drinking water. The author reminds us of the fact that the growing settlement around temples will wipe out the purity of the villages. The state of temples that have commercialized devotion is not different from this.

Through the forty-six chapters, Sarah Joseph is able to enliven the thought of the readers, and to evoke in them the necessity of conserving the originality of villages. Kumaran, who leaves his indigenous job and moves to city, loses the holiness of the village under the illusion that modernism and industrialization are meant for "development." Also, it awards Aathi with a population who receive diseases out of its failure to take care of nature adequately. The sight of Aathi, whose situation changes from a haven to a diseased centre, is central to the novel.

Aathi had been a land of no caste system or falsehood. The rule was that once the raconteurs arrive, story has to be told fully, irrespective of any difficulty. Through Noormohamed, Gitanjali, Maashu and Dhinakaran many tales speak this by accentuating the pragmatic life of Aathi. The chapters also have their own specialties. The chapter entitled "Shirt", revealing the family background of Dhinakaran, denotes people who have become slaves to consumerism. It also persuades us to think about, and regulate our desire to become models. Dhinakaran's thought that "the dirt made by us should be washed by ourselves" is applicable to us also. In the chapter "Vellatthinu Theliyathirikanavilla", the harmony between water and human mind is explained. Here, through the story of Buddha, the novelist unveils multiple facts. The girl in Aathi who herself takes up the collection of refuse is parallel to Anandan who cleansed himself when gathered water for Buddha. The picture is that when there is nothing to do, the mind becomes clear. Through the story of Noormohamed, the novelist shares with the reader the idea that the value of water is same as of life itself.

Aathi lies within the cycle of lukewarm water-bodies which is very similar to the foetus kept inside the protective layer of womb. The doors of the houses in Aathi have neither locks nor bolts. The concept of door-less houses was totally new to those outside Aathi. For people in Aathi, the image of a house with many rooms was beyond their imagination. They had nothing as "personal", hence, the city was alien to them. Though having many facilities, Kunjikaili's life in flat is agitated. The uneasiness in apartments is made clear here. Kunjikalli and Unnimon realise the hollowness of urban life. They move to Aathi and share their experience. They try to understand, in the light of their experience, the innocent people who are deceived by advertisements and gaudy appearances. It is Kunjimaathu who alone recognizes the real nature of Kumaran.
The story "Kayal" - meaning backwater - is a testament to the point that Aathi forgives and forgets all. Gitanjali reaches Aathi as a last resort to save her daughter. The waste contributed by the city to her inner and outer selves is taken up by the land and becomes a sanctuary. "Orukuppikallu Oru Poovankozhi" (One bottle toddy and one chicken) pinpoints how manmade God and religion are distant from himself. "Thampuran", a reflection of the people in Aathi, has been worshipped with all the human weaknesses. The so-called sophisticated people have separated God from people, and assigned special places for them. Here is an authentic expression of contemporary realities.

The people, especially of the elder generation, who have been guided by the pragmatic wisdom imparted by the chronicles of the evenings, are not attracted towards the showy assets and scenes of the city. A few of the new generation also foresee the impending dangers. They endeavoured to preserve Aathi with its all beauty. Dinakaran sacrificed his own life for the land in his struggle for virtue. He vanishes from Aathi with his exhortation for fellow people to learn his life and implement those ideals in their lives. His aim was the betterment of Aathi. He gives the message that life should have environmental goodness. The author sums up the novel by putting forward a vivid picture of colonization in the guise of "development", how these affect our surroundings and ourselves, and what precautions we have to take for saving ourselves.

We can find two modes of ecological perspective in the novel. One is of those who are in power and the other is that of the rural folk upon whom the power is exercised. The first spoils the pristine quality of the countryside. The second is about how to preserve this genuineness and how to regain the village. The novelist very clearly portrays the resistance of Kunjimaathu to the mechanical Kumaran who had left village for the sake of development. Shailaja and Kunjimaathu exemplify women, the creators of new generations, who act for the betterment of the village through resistance. Through the reflection on the full-length mirror, Unnimon grasps the realisation that we are so different from the mental pictures of ourselves. The picture of Unnimon, who realizes his reality and returning to his village with his mother from the city, is highly eligible for contemplation. "The man with black specs was in the tent"; instead of permanent houses, building temporary houses, and throwing them away after use; those flexible houses are able to fix everywhere. This subverts the concept of house. The tent raised at the opening of the novel is an image. The implication of their house has thus been shattered. The mirror conceals the reality of the face; face is the mirror of the mind. Hence, the man appears with black specs for hiding the emotional variations in his eyes. He, having no form and name, is a personification of the modern man. For his selfish ends, he hides his wild nature and there onwards, we can find the sight of his destruction of the purity of the village. 
Kumaran evinces that the person in Aathi himself spoils the sacredness of the hamlet. Kumaran, rejecting the traditional orders of work and migrating to the city, returns village with the urban culture. He pretends to have affection for Kunjimaathu and exploits her. Later, he defiles the holiness of Aathi. The picture of exploiting the innocence and curiosity of children, and thus attempting to pollute the sanctity of the generations, is visible. In the chapter 'Manthrikam" (magic), the magician appeases people through conjuring tricks; the sight of exhibiting various models and reshaping Aathi according to them. Through this, he is able to inculcate in the minds of the youth the notion of revealing the comforts and facilities of the city, and that our village should also be urbanized.

We can find in the novel a fresh perspective of ancient tales in the premises of contemporaneity. It urges to view incidents from the Mahabharatha, the Bible, Buddha-tales, and folklore with an added significance. The work is an apt example for a novel that enables ecological reading and consciousness. The novel puts forth the view that a woman is both Nature and "Shakthi". Kunjimaathu is a powerful embodiment of resistance. Overall, it is beyond question that "Aathi" holds, forever, a unique position in the history of the novel in Malayalam literature.

\section{CONCLUSION}

It is only when women approach current affairs from her own subjective perspectives that their literature gather strength enough to foreground the biased existence of social structures. In a sense Sara Joseph's writings remind us of what Elaine Schowalter has mentioned about women's writings. According to Schowalter only when we understand and observe women as authors as well as readers that this process of powerfully articulating gender and the myriad structures around it becomes meaningful. In the absence of such observation being made and incorporated by women authors they inevitably become consumers of a literary world that was engineered to cater to the tastes and pleasures of a male only inhabited world. Thus a language incorporating feminine experience of inhabiting this world becomes a fundamental requirement. According to Schowalter three factors become important in the context of women's writing, the feminine, the feminist and feminine subjectivist. Of these feminine is a trend to match up to the creative instincts of the male. The danger of this remains in the fact that it inevitably results in the borrowing of the same patriarchal frameworks. This also results in female authors competing with their male counterparts to present woman and her world in a stereotype language of patriarchy. The women being sketched here is the one predominantly cultivated in the male imaginations. The feminist mode of writing, on the other hand, attempts to render visibility to the difficulties and struggles that women face and undertake. Resisting, protesting and even revolting against the patriarchal structures is the hallmark of this genre of writing. The third mode, that is the subjectivist approach, ensures that the representation of the world is done from a strictly women's perspective. In this respect she is invited to reinvent her own self. What she called as gynocritics, considered a major mode of feminist literary criticism, is thus summed up in the following lines:

In contrast to [an] angry or loving fixation on male literature, the program of gynocritics is to construct a female framework for the analysis of women's literature, to develop new models based on the study of female experience, rather than to adapt male models and theories. Gynocritics begins at the point when we free ourselves from the linear absolutes of male literary history, stop trying to fit women between the lines of the male tradition, and focus instead on the newly visible world of female culture. $(1985,131)$

Of these Sara Joseph belongs to the second category, that is the feminist. She not only consistently engages herself in a fiery fight against the male hegemony and patriarchal ideologies, but she also takes a clear position in the resistance against larger oppressive elements. What gets reflected in this novel is the author's adamant stand that declares harmony in unambiguous terms with the political ideology of the lower class and caste divisions. She simultaneously declares her disagreement with the soft feminine love and woman's traditional role of being dependent of man. She is also not willing to yield herself into the glorified status of motherhood that, as she rightly recognizes, is the effective chain put in place to regulate her mobility within a social space. Sara believes that the individual frustrations and the social inequalities are products of the powerful elements of society who can retain their positions only through a reproduction of such inequalities. She foregrounds, what she conceives as "the" practical measure that only by fully incorporating women's liberation movements is the larger goal of human liberation as such is possible.

\section{REFERENCES}

[1] Denis Goulet, The Cruel Choice: A New Concept in Theory of Development, New York, Atheneum Press, pp. 20, 'Ibid 7 S, 1971.

[2] Joseph and Sara, Aathi, Kottayam: D C Books, 2011.

[3] C. Haris, Samakala Niroopanatthinte Vyathyastha Mukhangal”(Mal), Kottayam: DC Books, 2000.

[4] Mühlhäusler, Adrian, Peter and Peace, "Environmental Discourses", in Annual Review of Anthropology, Vol. 35, pp.457-479, 2006.

[5] Muraleedharan and Nellikkal, Viswa Sahithya Darshanangal (Mal), Kottayam: DC Books, 1999.

[6] P. K. Parameswaran, Malayala Sahithya Charithram (Mal), Kottayam: National Book Stall.

[7] Showalter and Elaine, New feminist criticism: essays on women, literature, and theory, NewYork: Pantheon Books, 1985.

[8] Vakoch, Douglas, Feminist Ecocriticism: Women, Environment and Literature, Lanham: Lexington Books, ed, 2012. 